\title{
An Approach to Determine the Weibull Parameters and Wind Power Analysis of Saint Martin's Island, Bangladesh
}

\author{
Khandaker Dahirul Islam, Dr. Natthawud Dussadee and Dr. Tanate Chaichana \\ School of Renewable Energy, Maejo University, Sansai, Chiang Mai 50290, Thailand
}

\begin{abstract}
This paper explores wind speed distribution using Weibull probability distribution and Rayleigh distribution methods that are proven to provide accurate and efficient estimation of energy output in terms of wind energy conversion systems. Two parameters of Weibull (shape and scale parameters $k$ and $c$ respectively) and scale parameter of Rayleigh distribution have been determined based on hourly time-series wind speed data recorded from October 2014 to October 2015 at Saint Martin's island, Bangladesh. This research has been carried out to examine three numerical methods namely Graphical Method (GM), Empirical Method (EM), Energy Pattern Factor method (EPF) to estimate Weibull parameters. Also, Rayleigh distribution method has been analyzed throughout the study. The results in the research revealed that the Graphical method followed by Empirical method and Energy Pattern Factor method were the most accurate and efficient way for determining the value of $k$ and $c$ to approximate wind speed distribution in terms of estimating power error. Rayleigh distribution gives the most power error in the research. Potential for wind energy development in Saint Martin's island, Bangladesh as found from the data analysis has been explained in this paper.
\end{abstract}

\section{Introduction}

Wind data analysis and accurate wind energy potential assessment is critical for proper and efficient development of wind power application and is highly sitedependent [1]. Bangladesh possesses nearly $580 \mathrm{~km}$ of coast in the southern part of the country along with a couple of offshore areas as well. Saint Martin's is one of those small islands situated about $15 \mathrm{~km}$ apart from Teknaf, the southern-most tip of Bangladesh mainland. Energy situation of the island depends fully on off-line power sources. Currently annual electric energy demand of the island is about $359 \mathrm{MWh}$ [2].

Due to the prominence of tourism, Saint Martin's island has been grown with commercial shops, restaurants and residential hotels which have their own or shared electricity mean of diesel generator. This stands as a mean to pollute the green environment of the island. A balanced, diversified, and environmental friendly energy system is the target for the whole world to curb problems associated with fossil fuel energy systems, which is the main cause of the worrying climate change [3]. Besides this, recent increases in the cost of fossil fuels have revived the interest in modern exploitation of energy from wind power [4].

But in order to get the maximum benefits from wind, detailed knowledge of wind characteristics and distribution are crucial parameters to select optimum wind energy conversion system to optimize energy output and minimization of electricity generation cost [5]. Wind resources are seldom consistent and vary with time of the day, season of the year, height above the ground, type of terrain, and from year to year, hence should be investigated carefully and completely [6]. Since Bangladesh lacks in having an accurate and reliable wind atlas, necessary attempts like pre-selecting wind sites, wind survey especially in coastal and offshore regions etc. could not be undertaken as it were needed to diagnose the wind potential of the country. It is expected that the importance of this economical issue and the environmental pollution problem associated with the use of oil, will boost over time the development of renewable energy resources, which have gained huge magnitude due to their sustainability, inexhaustibility and ecological awareness [7]. Renewable energy for the current research is estimated for Saint Martin's island wind data for a complete year. Weibull Probability Distribution Function (PDF) has been adopted in this research, for this method is usually considered as the most qualified function due to its simplicity and high accuracy [8]. Again Rayleigh distribution function has been also analysed in the research for better understanding of the wind. The Weibull PDF has been employed almost unanimously by researchers involved in wind speed analysis and it has also extensively been used in wind power analysis for many decades [9].

\section{Data source and methods}

The wind speed data recorded in every minute in a timeseries format over a one year (October 2014 - October 
2015) have been collected and statistically analyzed. Saint Martin's wind speed data were recorded at a height of 10 meter from the nearest local meteorological station situated in Teknaf, about thirteen kilometres apart from the island, and also the southern-most tip of Bangladesh mainland. Following is the table (Table 1 ) that provides the geographical information of the island.

Table 1. Geographical coordinates of Saint Martin's Island, Bangladesh

\begin{tabular}{|l|l|}
\multicolumn{2}{c|}{ Variables } \\
\hline Latitude & $20^{\circ} 34^{\prime}-20^{\circ} 39^{\prime} \mathrm{N}$ \\
\hline Longitude & $92^{\circ} 18^{\prime}-92^{\circ} 21^{\prime} \mathrm{E}$ \\
\hline Anemometer height & $10 \mathrm{M}$ \\
\hline Maximum elevation from sea level & $3 \mathrm{M}$ \\
\hline
\end{tabular}

Bangladesh counts six seasons in a year thought the country observes prominently three seasons namely summer, monsoon and winter. This paper analyzes the data in these three seasonal manners.

\section{Measurements of mean wind speed and standard deviation}

For every season comprised of four months in a year, the wind speed data recorded every minute are taken to sort out as hourly basis. Mean wind speed and standard deviation have been estimates using the following equations:

$$
\begin{gathered}
v_{m}=\frac{1}{N}\left(\sum_{i=1}^{N} v_{i}\right) \\
\sigma=\left[\frac{1}{N-1}\left(\sum_{i=1}^{N}\left(v_{i}-v_{m}\right)^{2}\right)\right]^{\frac{1}{2}}
\end{gathered}
$$

where, $v_{m}$ is the mean wind speed, $\mathrm{m} / \mathrm{s}, \sigma$ is standard deviation of the data $(\mathrm{m} / \mathrm{s}), v_{i}$ means hourly wind speed $(\mathrm{m} / \mathrm{s})$ and $N$ is the number of measured hourly wind speed data.

\section{Wind data analysis}

The wind speed at 10 metres from the ground was converted to the speed at 50 metres up from the ground using power law. The optimistic height from the ground is $40-70 \mathrm{~m}$, where the wind speed is high which is more applicable for wind energy generation [10]. The equation for power law is given here:

$$
\frac{v_{z}}{v_{z_{\text {ref }}}}=\left(\frac{z}{z_{\text {ref }}}\right)^{\alpha}
$$

and

$$
\alpha=\frac{0.37-0.088 \ln \left(v_{r e f}\right)}{1-0.088 \ln \left(\frac{z_{r e f}}{10}\right)}
$$

where, $V_{z}=$ wind speed at height $z, V_{Z r e f}=$ wind speed at reference height $\left(Z_{r e f}\right), Z=$ height above ground level, $Z_{\text {ref }}$
$=$ reference height, $\alpha=$ power law exponent. After calculating the wind speed at 50 metres from the above equation, monthly mean wind speed of the following table (Table. 2) can be identified using the following formula:

$$
V^{\prime}=\frac{i}{N} \sum_{i=1}^{N} m_{i} f_{i}
$$

The same formula can be applied to measure the mean wind speed for other two seasons. Now, the whole three seasons mean wind speeds are being displayed in Table 2 .

Table 2. Mean seasonal wind speed for Saint Martin's Island.

\begin{tabular}{|l|c|c|}
\hline \multicolumn{1}{|c|}{ Seasons } & $\begin{array}{c}\text { Mean wind } \\
\text { speed (10M) }\end{array}$ & $\begin{array}{c}\text { Mean wind } \\
\text { speed (50M) }\end{array}$ \\
\hline Summer & $\mathbf{m} / \mathbf{s}$ & $\mathbf{m} / \mathbf{s}$ \\
\hline Monsoon & 2.74 & 4.23 \\
\hline Winter & 2.91 & 4.45 \\
\hline Whole year & 2.39 & 3.76 \\
\hline
\end{tabular}

Wind resources are seldom consistent and vary with time of the day, season of the year, height above the ground, type of terrain, and from year to year, hence should be investigated carefully and completely [11]. So it needs more to investigate how wind behaves in different times in a year. That's why, after finding the mean speeds of different time range (daily, hourly, monthly etc.), some of figures in the following sections can be shown in order to understand the wind characteristics. Study of wind velocity regime over a period of time in a locality can really help to optimize the design of the wind energy conversion system by ensuring less energy generating costs [12]. It can be shown that how wind interact in everyday of a year. For 365 days of a year to show in a figure is difficult to understand, that's why hourly and monthly figure should also be analysed for more better understanding.

Wind speed recorded over minutely or hourly basis over 24 hours in a day, and thus is continued to record the data for a couple of months, or even a number of years. Average wind speed for a complete year with respect to 24 hours is so far the best way to represent wind characteristics. It means that, the first hour of every day of the year is recorded and averaged. In this way, the other hours average wind speed is calculated. The complete frequency distribution of the year or the month is expected only by annual or monthly average wind [13]. In order to determine frequency distribution of the wind speed, it is a must first to divide the wind speed domain into a number of intervals, mostly of equal width of $1 \mathrm{~m} / \mathrm{s}$ [14].

\section{Determination of probability distribution}

Weibull distribution can be characterized by its probability density function $f(v)$ and cumulative distribution function $F(v)$ as follows [15]:

$$
f(v)=\left(\frac{k}{c}\right) \cdot\left(\frac{v}{c}\right)^{k-1} \cdot \exp \left(-\left(\frac{v}{c}\right)^{k}\right)
$$


and

$$
F(v)=1-\exp \left(-\left(\frac{v}{c}\right)^{k}\right)
$$

where; $f(v)$ is the probability of observing wind velocity $v_{i}$, $\mathrm{F}(\mathrm{v})$ is the cumulative distribution function, $c$ is the Weibull scale parameter $(\mathrm{m} / \mathrm{s})$ and $k$ is the dimensionless Weibull shape parameter. There are many methods to estimate $k$ and $c$. Three methods upon which the structure of the research is grown are being analysed in the following sections.

\subsection{Graphical method}

In this method, the wind speed data are interpolated by a straight line, using the concept of least squares regression [16], [17]. Equation (7) is converted to a logarithm form like the following:

$$
\ln (-\ln (1-F(v))=k \cdot \ln (v)-k \cdot \ln (c)
$$

Now, the Weibull shape and scale parameters are estimated by plotting $\ln (v)$ against $\ln (-\ln (1-F(v))$ in which a straight line is derived. The shape parameter $\mathrm{k}$ is determined by the slope of the line, and scale parameter from the following relation: $-k \cdot \ln (c)=y$-intercept.

\subsection{Empirical method}

Shape and scale parameter $\mathrm{k}$ and $\mathrm{c}$ are measured in this method by the following equations. Shape and scale parameters in this method are estimated from the mean wind speed $\left(v_{m}\right)$ and standard deviation $(\sigma)$ of wind data.

$$
k=\left(\frac{\sigma}{\overline{v_{m}}}\right)^{-1.086}
$$

Once getting $\mathrm{k}$ from equation $9, \mathrm{v}_{\mathrm{m}}$ and $\mathrm{k}$ help finding $\mathrm{c}$ from the following equation:

$$
c=\frac{v_{m}}{\Gamma\left(1+\frac{1}{k}\right)}
$$

where $\Gamma$ is the standard Gamma function expressed as:

$$
\Gamma=\int_{0}^{\infty} t^{x-1} e^{-t} d t
$$

Gamma function was used by Manwell et al. [18], and can be expressed as:

$\Gamma(x)=\sqrt{2 \pi x} \cdot x^{x-1} \cdot e^{-x} \cdot\left(1+\frac{1}{12} x+\frac{1}{288} x^{2}-\frac{139}{58140} x^{3}+\ldots ..\right)$

\subsection{Energy pattern factor method}

This method to estimate $k$ and $c$ is related to the averaged data of wind speed. It has simpler formulation, easier implementation and also requires less computation. The method is defined by the following equations:

$$
E_{p f}=\frac{\left(v^{3}\right)_{m}}{\left(v_{m}\right)^{3}}
$$

where $\left(v^{3}\right)_{m}$ is denoted as the mean of the cubed wind speed, and can be mathematically written as:

$$
\left(v^{3}\right)_{m}=\frac{1}{N} \sum_{i=1}^{N} v_{i}^{3}
$$

And $\left(v_{m}\right)^{3}$ is the cube of mean wind speed. This can be shown as equation (15):

$$
\left(v_{m}\right)^{3}=\left(\frac{1}{N} \sum_{i=1}^{N} v_{i}\right)^{3}
$$

here $E_{p f}$ is called energy pattern factor. Once $E_{p f}$ is calculated from equation 13 , Weibull shape parameter $k$ can be estimated as:

$$
k=1+\frac{3.69}{\left(E_{p f}\right)^{2}}
$$

Once $k$ is found, from the equation, scale parameter $c$ can be measured from the following, as equation (17) shows:

$$
v_{m}=c \Gamma\left(1+\frac{1}{k}\right)
$$

where $\Gamma$ is known as Gamma function as expressed in equation (11) and (12).

\subsection{Rayleigh probability distribution function}

\begin{tabular}{|c|c|c|c|c|c|c|}
\hline \multirow[t]{3}{*}{ Methods } & \multicolumn{2}{|c|}{ Summer } & \multicolumn{2}{|c|}{ monsoon } & \multicolumn{2}{|c|}{ winter } \\
\hline & \multirow[t]{2}{*}{$\boldsymbol{K}$} & $C$ & \multirow[t]{2}{*}{$\boldsymbol{k}$} & \multirow{2}{*}{\begin{tabular}{|c|}
$c$ \\
$\mathbf{m} / \mathbf{s}$
\end{tabular}} & \multirow[t]{2}{*}{$\boldsymbol{k}$} & \multirow{2}{*}{$\begin{array}{c}c \\
\mathbf{m} / \mathbf{s}\end{array}$} \\
\hline & & $\mathbf{m} / \mathbf{s}$ & & & & \\
\hline Graphical Method & 1.46 & 4.18 & 1.43 & 4.52 & 1.53 & 3.94 \\
\hline Empirical Method & 1.57 & 4.71 & 1.76 & 4.99 & 1.93 & 4.22 \\
\hline $\begin{array}{l}\text { Energy Pattern } \\
\text { Factor }\end{array}$ & 1.66 & 4.78 & 1.91 & 5.11 & 2.05 & 4.28 \\
\hline $\begin{array}{l}\text { Rayleigh } \\
\text { Distribution }\end{array}$ & 2 & 4.77 & 2 & 5.02 & 2 & 4.23 \\
\hline
\end{tabular}

If $c$ is obtained from equation (8) by putting $\mathrm{k}=2$, then probability distribution functions for Rayleigh distribution can be found like the following equation:

$$
v_{m}=c \Gamma\left(1+\frac{1}{2}\right)
$$

Now from the above methods explained, the shape and scale parameters $\mathrm{k}$ and $\mathrm{c}$ are found like the following table (Table 3):

Table 3. $k$ and $c$ for Weibull and Rayleigh distribution

\section{Result}

\subsection{Weibull probability measurement}

The following figure shows for each season the Weibull Frequency plotted with the measured wind speed. These 
curves illustrate the Weibull methods that fit best to the measured wind speed data.
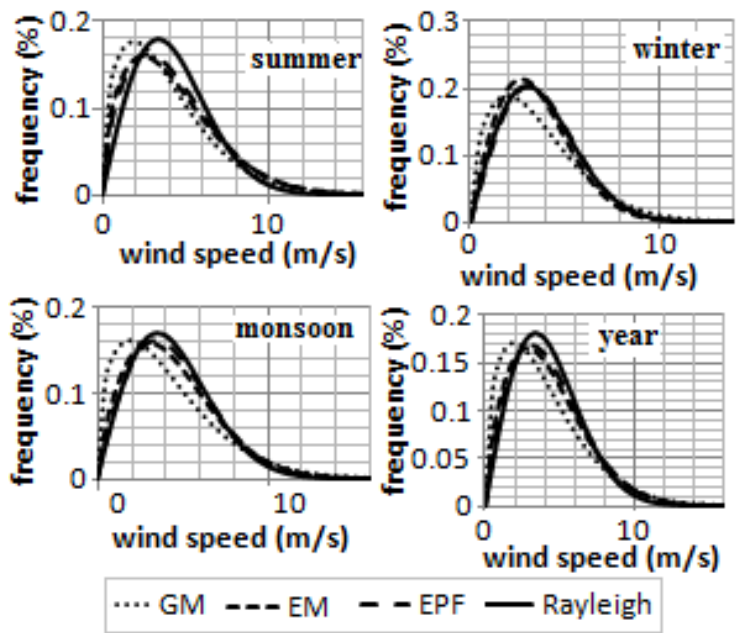

Figure 1. Weibull frequency against wind speed frequency distribution

\subsection{Wind power density calculations}

The available power of the wind that crosses the rotor of a wind turbine generator is [19]:

$$
p_{w}(v)=\frac{1}{2} \rho A v^{3}
$$

where $p_{\mathrm{w}}(v)$ is the power associated with wind speed $v ; A$ is the rotor area; and $\rho$ is the air density (typically 1225 $\mathrm{kg} / \mathrm{m} 3$ at sea level [20]). But when evaluating the available energy at a wind site, the following function which is known as wind power density distribution is used:

$$
e_{w}(v)=\frac{1}{A} f(v) p_{w}(v)
$$

This function represents wind energy distribution at different wind speed per unit of time and rotor area in the unit of $\mathrm{W} / \mathrm{m}^{2}$, where $\mathrm{f}(\mathrm{v})$ is known as Webull Probability Distribution Function (PDF).

Wind Power Density (WPD) based on the Weibull PDF (with the help of $k$ and $c$ ) can be calculated using expression given as [21]:

$$
p(v)=\frac{1}{2} \rho c^{3} \Gamma\left(1+\frac{3}{k}\right)
$$

where, $p(v)$ is the wind power density in $\mathrm{W} / \mathrm{m}^{2}, \rho$ is the air density at the site, $\left(\mathrm{kg} / \mathrm{m}^{3}\right), k$ and $c$ are shape and scale parameters for Weibull distribution, $\Gamma$ is Gamma function as described in equation (12). Equation (21) determines the average power density for different seasons that is shown in the following figure.

From Figure 2 it is clear that, monsoon and winter have the highest and lower average power respectively. Figure 2 also identifies that empirical and energy pattern factor method give good power output for summer, monsoon and yearly gain.

For monsoon and winter season as shown in Figure 2, graphical method tops in giving power. However, Rayleigh method lags in all the seasons with an exception of winter. Rayleigh places third in the winter.

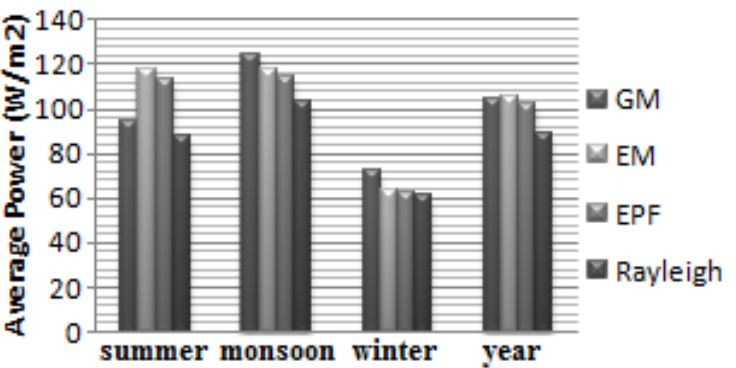

Figure 2. Average wind power of all seasons and year vs. distribution methods
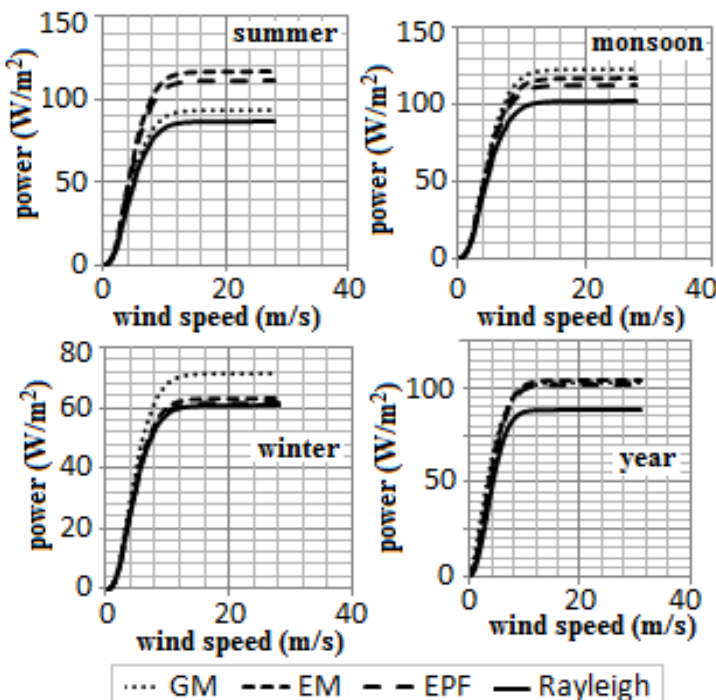

Figure 3. Cumulative power distribution for three seasons

Now, Figure 3 above shows the cumulative power distribution for three seasons. Yearly gain of the wind power as the data analysis generates is also shown in the figure.

\subsection{Relative error of the available power density}

In order to determine if a particular Probability Distribution Function is suitable to describe the wind speed data, indicators can be used. For each wind site and fitting method, this paper considers power density errors to understand the wind power for different seasons for different distribution methods. The errors in calculating the power densities using the distribution models (Weibull and Rayleigh) in comparison to the values of the probability density distributions derived from Field data values can be found using the following formula [22]:

$$
\text { error }_{P D F}=\frac{P_{P D F}-P_{m}}{P_{m}} \times 100 \%
$$

where error $_{P D F}$ is the error in calculating power densities with probability distribution function models, $\mathrm{P}_{\mathrm{PDF}}$ is denoted as the wind power density for the probability distribution functions, and $\mathrm{P}_{\mathrm{m}}$ is the power derived from the data directly.

With equation (22), deriving the error for different distribution methods for three seasons signifies the usability of the methods to choose for the current data.

Power of summer season for graphical and Rayleigh methods give biggest error. For monsoon and winter 
season, it is seen that, in terms of giving smaller error, the ranks are GM, EM, EPF and Rayleigh. For the whole year data analysis, almost same scenario generates with an exception of GM and EM. For whole year power error analysis EM is followed by GM.

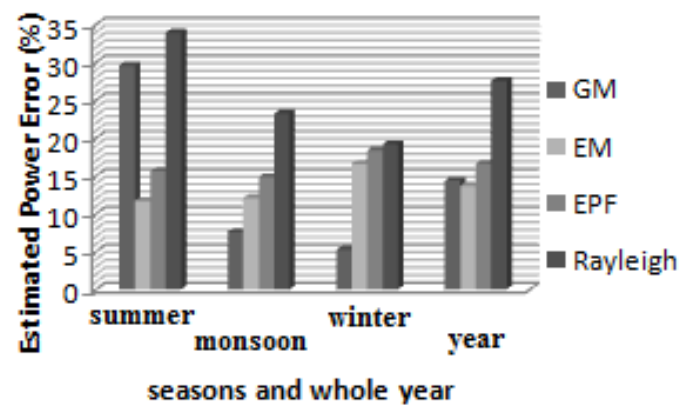

Figure 4. Relative error of power density

\section{Conclusions}

The hourly wind speed data in time-series format from October 2014 to October 2015 for Saint Martin's island, Bangladesh have been statistically analyzed based on Weibull and Rayleigh PDF. The aim of the study was to investigate the wind power of the island with different shape and scale parameters within Weibull PDF domain. The research as the result has been produced, suggests that suitability of the methods used here may vary with the sample data size, sample data distribution, sample data format etc. is an efficient method for determining the $k$ and $c$ parameters to fit Weibull distribution for the wind speed data at Saint Martin's island. The most important outcomes of the study can be written as follows:

1. $k$ and $c$ for Weibull and Rayleigh PDF have been measured.

2. Maximum wind power was derived in the season of monsoon.

3. Rayleigh distribution estimates less power for all seasons.

4. Graphical method gives less error in terms of power calculations with an exception in summer season.

5. MM and EPF method exhibit consistency in giving power error for all seasons (Figure 4).

6. The wind of Saint Martin's island gives power densities between $(88.36$ - 118.07) W/m², $(103.00-125.05) \mathrm{W} / \mathrm{m}^{2}$ and $(61.62-72.28)$ $\mathrm{W} / \mathrm{m}^{2}$ for summer, monsoon and winter seasons respectively with different distribution methods at 50 meters height. This has been shown in Figure 3.

7. The power from the wind is satisfactory for the island.

The most widely used methods were selected for Weibull analysis here. Power errors are sought to be significantly less in this research.

\section{References}

1. S. Darbandi, M. T. Aalami, H. Asadi, Comparison of Four Distributions for Frequency Analysis of Wind
Speed, Environment and Natural Resources Research, 2(1):96-105, (2012)

2. Electricity demand survey report at the St. Martin's Island, SRE, LGED, Dhaka, Bangladesh, (May 2004)

3. M. Grein, B. Nordell, A. Al Mathnani, Energy consumption and future potential of renewable energy in North Africa, Revue des Energies Renouvelables ICRESD-07 Tlemcen, (2007) 249-254.

4. T. Chaichana, S. Chaitep, Wind power potential and characteristic analysis of Chiang Mai, Thailand, Journal of Mechanical Science and Technology, 24(7):1475-1479, (2010)

5. R. Pallabazzer, Parametric analysis of wind siting efficiency, J. Wind Eng. Indus. Aerod., 91:1329-52, (2003)

6. S. Rehman, Long-Term Wind Speed Analysis and Detection of its Trends Using Mann- Kendall Test and Linear Regression Method, Arabian Journal for Science and Engineering, 38(2):421-437, (2013)

7. D. K. Kidmo, R. Danwe, S. Y. Doka, N. Djongyang, Statistical analysis of wind speed distribution based on six Weibull Methods for wind power evaluation in Garoua, Cameroon, Revue des Energies Renouvelables, 18(1):105-125, (2015)

8. A. Mostafaeipour, M. Jadidi, K. Mohammadi, A. Sedaghat, An Analysis of Wind Energy Potential and Economic Evaluation in Zahedan, Iran, Renewable and Sustainable Energy Reviews, 30:641-650, (2014)

9. A. N. Celik, Energy Output Estimation for SmallScale Wind Power Generators Using WeibullRepresentative Wind Data, Journal of Wind Engineering and Industrial Aerodynamics, 91(5): 693-707, (2003)

10. A. Roy, Reliable estimation of Density Distribution in Potential Wind Power Sites of Bangladesh, International Journal of Renewable Energy Research, 2(2), (2012)

11. S. Rehman, Long-Term Wind Speed Analysis and Detection of its Trends Using Mann- Kendall Test and Linear Regression Method, Arabian Journal for Science and Engineering, 38(2):421-437, (2013)

12. K. Ulgen, A. Hepbasli, Determination of Weibull parameters for wind energy analysis of Izmir, Turkey. Int. J. Energy Res., 26(6):495-506, (2002)

13. A. K. Azad, M. M. Alam, A Statistical Tools for Clear Energy: Weibull's Distribution for Potentiality Analysis of Wind Energy, International Journal of Advanced Renewable Energy Research, 1:240-247, (2012)

14. E. H. Lysen, Introduction to Wind Energy, Consultancy Services Wind Energy Developing Countries, CWO 82, Second Edition, (1983)

15. A. N. Celik, A Statistical Analysis of Wind Power Density Based on the Weibull and Rayleigh Models at the Southern Region of Turkey, Renewable Energy, 29(4):593-604, (2004)

16. P. A. C. Rocha, R. C.o de Sousa, C. F. de Andrade, M. V. da Silva, Comparison of Seven Numerical Methods for Determining Weibull Parameters for Wind Energy Generation in the Northeast Region of Brazil, Applied Energy, 89(1):395-400, (2012) 
17. C. G. Justus, W. R. Hargraves, A. Mikhail, D. Grabber, Methods for Estimating Wind Speed Frequency Distributions, Journal of Applied Leteorology, 17(3):350-353, (1978)

18. J. F. Manwell, J. G. McGowan, A. L. Rogers, Wind Energy Explained: Theory, Design and Application, John Wiley and Sons Ltd, (2002)

19. T. Burton, D. Sharpe, N. Jenkins, E. Bossanyi, Wind Energy Handbook, Chichester, UK: John Wiley \& Sons, Ltd., (2001)

20. Wind Turbines-Part. 12-1: Power Performance Measurements of Electricity Producing Wind Turbines; IEC 61400-12-1 Edition 1.0; International
Electrotechnical Commission (IEC): Geneva, Switzerland, (2005)

21. H. S. Bagiorgas, G. Mihalakakou, S. Rehman, L. M. Al-Hadhrami, Wind Power Potential Assessment for Seven Buoys Data Collection Stations in Aegean Sea Using Weibull Distribution Function, Journal of Renewable and Sustainable Energy, 4(1):013119-1 013119-16, (2012)

22. N. C. Ali, A Statistical Analysis of Wind power Density Based on The Weibull and Rayleigh Models at the Southern Region of Turkey. Renewable Energy, 29:593-604, (2003) 